\title{
Las concesiones de obra pública: ¿qué son y por qué se utilizan en Chile? ? $^{* * * * * *}$
}

\section{Public works concessions: what are they and why does Chile use them?}

\section{RESUMEN}

El presente trabajo intenta responder tres preguntas desde la perspectiva del derecho chileno: qué son las concesiones de obra pública, por qué se las denomina "asociaciones público-privadas" y qué justificaciones se han dado para su utilización en Chile. Para alcanzar estos objetivos se tienen en cuenta las normas legales chilena, española, italiana y colombiana, de las cuales es posible concluir que el contrato de concesión es un contrato de ejecución de infraestructura pública, caracterizado por la modalidad de pago del contratista denominada "derecho de explotación”. Luego se estudian las modificaciones introducidas en el ordenamiento chileno por la Ley 20.410 de 2010 que, se sostiene, permiten calificar al contrato como una "asociación público-privada". Finalmente, se analizan las justificaciones que la doctrina jurídica y la doctrina económica han elaborado para explicar estos contratos administrativos.

PALABRAS CLAVE

Concesiones de obras públicas, asociaciones público-privadas, ley de concesiones de obras públicas, Ley Orgánica del Mop, Ley 20.410.

Profesor asociado de Derecho Administrativo en la Facultad de Derecho de la Pontificia Universidad Católica de Valparaíso (Chile). Doctor en Derecho por la II Universidad de Roma “Tor Vergata" (Italia). Contacto: martin.loo@ pucv.cl ORCID ID: 0000-0002-9286-0969.

Recibido el 22 de abril de 2018, aprobado el 11 de junio de 2019.

Para citar el artículo: Loo GutiérRez, M. Las concesiones de obra pública: ¿qué son y por qué se utilizan en Chile? En Revista Derecho del Estado, Universidad Externado de Colombia. N. ${ }^{\circ} 44$, septiembre-diciembre de 2019, pp. 327-359.

DOI: https://doi.org/10.18601/01229893.n44.12

*** La realización de esta investigación fue financiada por la Comisión Nacional de Investigación Científica y Tecnológica a través del Proyecto Fondecyt de Iniciación en la Investigación n. ${ }^{\circ} 11160169$. 
ABSTRACT

The paper tries to answer three questions from a Chilean perspective: what are public works concessions, why are they called "public-private partnerships" and what justifies them in Chile. To reach these objectives the author considers the Chilean, Spanish, Italian and Colombian law from where it is possible to conclude that public works concession contract is a public works contract with a special way of reimbursement. The paper studies the amendments introduced to Chilean Law by Act N..$^{\circ} 20.410$ of 2010 . According to the author these amendments change the comprehension of the public works concessions contract and allow to name it as "public-private partnerships". Finally, the author analyzes the arguments developed by legal and economy scholars to explain the rationale of these administrative contracts.

KEYWORDS

Public Works Concessions, Public Private Partnerships, Public Works Concessions Act (Chile), Secretary of Public Works (Chile), Act N. ${ }^{\circ} 20.410$ (Chile).

SUMARIO

Introducción. 1.¿Qué es una concesión de obra pública? ¿Por qué se las llama "asociaciones público-privadas"? 2. ¿Por qué se utilizan las concesiones? Conclusiones interlocutorias. Referencias.

\section{INTRODUCCIÓN}

Desde los años noventa del siglo xx, las concesiones de obra pública son el principal método de ejecución de infraestructura pública en Chile. Las grandes obras públicas puestas en servicio durante el último cuarto de siglo han sido ejecutadas mediante esta modalidad de contratación administrativa. Es en virtud de contratos de concesión de obra pública que Chile ha visto surgir túneles, autopistas urbanas e interurbanas, aeropuertos, embalses, centros de cumplimiento penitenciario, hospitales, edificios para el funcionamiento de instituciones públicas y otras obras de infraestructura de similar envergadura e importancia.

Si se tuviera que medir el éxito del sistema de concesiones de obra pública chileno considerando solo la cantidad de infraestructura que ha sido capaz de poner en operación, estaríamos obligados a reconocer que es un gran éxito. Para comprobarlo basta el simple ejercicio de dar un paseo en automóvil por la zona central del país: la posibilidad de (verse obligado a) utilizar alguna obra de infraestructura concesionada en el Gran Santiago o en el Gran Valparaíso es bastante elevada. A la luz de tal constatación debería admitirse que Chile 
cuenta con un modelo exitoso y consolidado de ejecución de obras públicas por medio de concesiones, y que ello se debe a la experiencia acumulada en las dos décadas transcurridas desde la primera licitación de esta clase de contratos. En términos sencillos, habría que afirmar que el sistema de concesiones chileno ha madurado y sabido entregar, tanto a la población como a la Administración del Estado, infraestructura antes inexistente.

Resulta curioso que, pese a la importancia de las concesiones para la realización de políticas públicas en el plano económico y social, ellas hayan atraído, al menos en Chile, pocos estudios jurídicos que busquen entender la racionalidad de este método de ejecución de obra pública. De esta suerte, existen una serie de preguntas cuya falta de respuesta demuestra la necesidad de estudiar el sistema de concesiones de obra pública desde la perspectiva propia del derecho y, en particular, del derecho administrativo, sin renunciar al uso de insumos de otras disciplinas más prolíficas en el estudio de esta materia, como la economía.

Algunas de dichas preguntas corresponden a las más elementales acerca de un sistema concesional: ¿qué se entiende en Chile por concesiones de obra pública y en qué se diferencian o asemejan a aquello que en el derecho comparado se denomina "asociación público-privada"? ¿Por qué razón se han utilizado y, sobre todo, por qué se siguen utilizando? ¿Qué las diferencia del contrato de obra pública? ¿Son "mejores" que este último? Y, si son mejores que este último contrato, ¿lo son para todos los tipos de obras?

El presente artículo se plantea como un esfuerzo de reflexión sobre estas temáticas, ampliamente estudiadas por el derecho comparado, la ingeniería y la economía, pero más bien abandonadas por el derecho chileno ${ }^{1}$. En Chile, la mayor parte de la literatura que intenta hacerse cargo de entender la racionalidad de las concesiones de obra pública proviene de la pluma de ingenieros o economistas, quienes, con una mirada aguda y crítica, han avanzado camino en explicar por qué las concesiones parecen ser un buen mecanismo de ejecución de obras públicas, si bien no en todos los casos.

A la luz de lo anterior, resulta necesario que el derecho se reapropie de esta problemática y que se reflexione sobre la materia. Por este motivo, el presente artículo -que se inserta dentro de un proyecto de investigación más amplio sobre la temática- busca hacerse cargo de entender la operación jurídica denominada concesión de obra pública, intentando elaborar una

1 La verdad es que este fenómeno se reproduce en el derecho extranjero. Así, en la doctrina española pueden encontrarse frases del siguiente tenor: "los autores somos conscientes de la vertiente técnica, económica, o incluso política, que la construcción de obras públicas implica; y sabemos que, en ocasiones, la importancia de estos 'otros' aspectos puede superar o tratar de imponerse, con mayor o menor fundamento según el caso, al punto de vista jurídico". Menéndez Menéndez, A. Prefacio. En Menéndez Menéndez, A. (ed.), Instrumentos españoles de colaboración público-privada: el contrato de concesión de obras públicas. 2. ${ }^{a}$ ed. Cizur-Menor: Civitas, 2010, 11. 
noción actualizada de la misma que tenga en cuenta los importantes cambios introducidos en la regulación por la Ley 20.410 de 2010 (1); así mismo, se exponen las motivaciones que, en el derecho comparado y en el derecho chileno, se han invocado para dar cabida a esta modalidad de ejecución de infraestructura, proponiendo una crítica a las justificaciones de índole dogmática comunes en Chile y avanzando (aunque no elaborando, pues ello será objeto de otro artículo) una explicación que se haga cargo e integre las razones que la ingeniería y la economía han desarrollado para discernir qué hace mejor una concesión de obra pública de un contrato de obra pública y cuáles son las condiciones para que dichas razones se configuren (2). Por último, se ofrecen algunas conclusiones interlocutorias que se desprendan de estas reflexiones, la más importante de las cuales es que la Ley 20.410 alteró la comprensión del contrato de concesión ampliando su objeto, de modo tal que hoy algunas de sus modalidades coinciden con aquello que en el derecho extranjero se denomina "asociación público-privada".

1. ¿QUÉ ES UNA CONCESIÓN DE OBRA PÚBLICA? ¿POR QUÉ SE LAS LLAMA "ASOCIACIONES PÚBLICO-PRIVADAS"?

A diferencia de cuanto ocurre en los ordenamientos español, italiano y colombiano, el derecho chileno no define la concesión de obra pública ni las asociaciones público-privadas. Esta es la primera dificultad para determinar qué son las concesiones de obra pública en Chile y por qué razón se las llama, de un modo algo indiscriminado, "asociaciones público-privadas" (APP).

Chile cuenta con una legislación relativamente moderna en materia de concesiones de obra pública que, sin embargo, se limita a identificar sin demasiada precisión los elementos que configuran el contrato. Ha recaído en la doctrina la tarea de elaborar un concepto sobre esta clase de operaciones jurídico-económicas. Resulta curioso que, a pesar de no contar con una ley sobre APP, la doctrina pueda constatar que la legislación chilena sobre concesiones de obra pública se considera como un ejemplo de regulación exitosa de las $\mathrm{APP}^{2}$.

La concesión de obra pública se encuentra regulada en Chile en dos cuerpos legales. El primero de ellos es la Ley Orgánica del Ministerio de Obras Públicas -LO MOP- (Decreto con fuerza de ley 850, de 1997, del Ministerio de Obras Públicas), la cual, en su artículo 87, autoriza que la ejecución, reparación o mantención de las obras públicas fiscales de competencia de dicho ministerio sea realizada a cambio de la concesión temporal de su explotación. Esta disposición es desarrollada por la Ley de Concesiones de Obras

2 Moraga Klenner, C. ¿Hace falta una ley de asociaciones público-privadas en Chile? En BenAVIDES, J. L. (ed.), Estudios sobre el régimen jurídico de las asociaciones público-privadas. Bogotá: Universidad Externado de Colombia, 2014, 105. 
Públicas, contenida en el Decreto Supremo 900, de 1996, del Ministerio de Obras Públicas, por medio del cual se fijó el texto refundido del Decreto con fuerza de ley 164, de 1991, del Ministerio de Obras Públicas. El artículo $1 .{ }^{\circ}$ de esta ley establece:

La ejecución, reparación, conservación o explotación de obras públicas fiscales, por el sistema establecido en el artículo 87 [de la LO MOP], las licitaciones y concesiones que deban otorgarse, ya se trate de la explotación de las obras y servicios; del uso y goce sobre bienes nacionales de uso público o fiscales, destinados a desarrollar las áreas de servicios que se convengan; de la provisión de equipamiento o la prestación de servicios asociados, se regirán por las normas establecidas en el presente decreto con fuerza de ley, su reglamento y las bases de la licitación de cada contrato en particular, que el Ministerio de Obras Públicas elabore al efecto.

Como se aprecia, el legislador chileno se ha limitado a establecer normas que habilitan a la Administración del Estado para celebrar un cierto tipo de contrato. Dicho contrato puede tener una pluralidad de objetos y modalidades de cumplimiento que deben realizarse "a cambio de la concesión de [la] explotación" de las obras que se hayan ejecutado (art. 87 LO MOP). En otras palabras, el legislador chileno, a diferencia de cuanto ocurre en el derecho extranjero de referencia, ha renunciado a elaborar una noción preceptiva de la concesión de obra pública que se haga cargo de enunciar la finalidad principal del contrato y de las modalidades de remuneración del contratista.

En el sistema jurídico chileno ha sido la doctrina la que ha debido elaborar una noción del contrato de concesión de obra pública. De esta manera, por ejemplo, Vargas Fritz, luego de un extenso análisis de la concesión en general y de la doctrina extranjera clásica sobre la materia, concluye que la concesión de obra pública es:

... un contrato administrativo celebrado entre el Ministerio de Obras Públicas y un particular concesionario, en virtud del cual este último asume, a su cuenta y riesgo, la ejecución, reparación o conservación de una obra pública fiscal a cambio del derecho a explotar dicha obra y a obtener la tarifa o peaje pactados, dentro del plazo y de acuerdo a las condiciones legales y reglamentarias contenidas en el decreto supremo de adjudicación ${ }^{3}$.

El concepto recién transcrito adscribe a la concesión de obra pública una serie de características que, al día de hoy, merecen una mejor reflexión, como la circunstancia de que la concesión se convenga a "cuenta y riesgo" del concesionario; que su objeto sea solo la "ejecución, reparación o conservación 
de una obra pública", o que la contraprestación del concesionario se limite a la "tarifa o peaje" pactados. La evolución vivida por la legislación chilena en esta materia -en especial luego de la aprobación de la Ley 20.410- hace necesario revisar la vigencia de las conclusiones alcanzadas hace ya veintidós años por el autor.

Antes, sin embargo, es preciso recordar que tan solo dos años después del trabajo de Vargas -en 1999- la doctrina chilena se enriquecía con una segunda obra monográfica sobre este contrato, esta vez de Dolores Rufián Lizana. La autora, al definir la concesión de obra pública, manifestaba su coincidencia con la noción elaborada por Vargas, separándose en solo dos aspectos. El primero se relaciona con las partes del contrato que, según la autora, no son el MOP y el concesionario, sino el Estado y el concesionario. Y el segundo dice relación con la pretendida ejecución del contrato a "cuenta y riesgo" del concesionario. A este respecto sostiene que la Ley de Concesiones, en realidad, establece un sistema de "riesgos compartidos", encontrándose el contrato, por ello, regido por el principio del "equilibrio financiero"4.

Puede apreciarse que, en lo sustancial, la doctrina chilena concuerda en que el contrato de concesión de obra pública puede definirse como aquel en virtud del cual el Estado encomienda a un contratista la ejecución de una obra pública cuyo precio será pagado permitiéndole (es decir, concediéndole) la explotación económica de los servicios que puedan prestarse por medio de ella. De esta manera, la doctrina afirma que "el contrato de concesión de obras públicas es una suerte de combinación entre el contrato de obra y la concesión de servicios, en donde el privado se compromete a financiar y a realizar una obra nueva, a conservarla o repararla, y la remuneración proviene del producto de la explotación de la obra"5.

La concesión de obra pública es, en buenas cuentas, una modalidad de realización de infraestructura de uso o de utilidad pública, tal como lo es el contrato de obra pública ${ }^{6}$. Por ello, el objeto común y principal de ambos

4 Rufián Lizana, D. Manual de concesiones de obras públicas. Santiago: Fondo de Cultura Económica, 1999, 26. Véase también la segunda edición de esta obra, RuFián LizAnA, D. Manual de concesiones de obras públicas. 2. ${ }^{\text {a }}$ ed. Santiago: Andros, 2018, 28, sin cambios en este aspecto. Sobre este punto, críticamente, véase Loo GutiérRez, M. La distribución de los riesgos en el contrato de concesión de obra pública. En Bermúdez Soto, J. (ed.), Perspectivas para la modernización del derecho de la contratación administrativa. Actas de las XI Jornadas de Derecho Administrativo (2014). Valparaíso: Ediciones Universitarias de Valparaíso, 2016, 191.

5 Rufí́n Lizana. Manual de concesiones de obras públicas, cit., 23. En sentido similar, Bon, P. El régimen de las concesiones administrativas. En Revista de Derecho Administrativo Económico. Vol. 15, 2005, 4, sostiene que el aspecto que mejor distingue la concesión de obras y la concesión de servicio se encuentra en su objeto: "el objeto de la concesión de obras públicas es la realización de obras públicas y la explotación de la obra resultante, sin necesidad de que ella sea, en principio, servicio público. Sin embargo, en el caso particular, por lo demás frecuente, en que la explotación de la obra sea constitutiva de una actividad de servicio público, es a la vez una concesión de obras pública y de servicio público".

6 Moraga Klenner, C. La actividad formal de la Administración del Estado. Santiago: 
contratos administrativos no es otro que la realización de una obra pública, con el fin de satisfacer el objetivo del Estado de procurar infraestructura para el servicio público ${ }^{7}$. Aquello que diferencia al contrato de obras del contrato de concesión de obras no es, por tanto, su objeto principal, sino el modo en el cual se financia la realización de la obra y la remuneración del contratista, esto es, a través del "derecho de explotación". Tal como indica Dromi, "la concesión de obra pública es un sistema de contratación particularizado por la modalidad del pago del precio", toda vez que la remuneración del contratista consiste en el otorgamiento de la explotación de la nueva obra construida ${ }^{8}$. La relevancia de este derecho de explotación es bien explicitada por Rufián Lizana al sostener que "la característica esencial de la concesión de obra pública es la explotación de la misma"9.

A diferencia de cuanto ocurre en el derecho chileno, en algunos ordenamientos extranjeros es posible encontrar definiciones de la concesión de obras en las respectivas leyes sobre contratos administrativos. Dichas normas destacan la simbiosis recién indicada entre el contrato de obras y el contrato de concesión de obras públicas de una manera bastante clara.

Así, en el ordenamiento español, los artículos 13 y 14 de la Ley 9/2017, del 8 de noviembre, de Contratos del Sector Público (LCSP) ${ }^{10}$, establecen, respectivamente, las definiciones del contrato de obras y del contrato de concesión de obras.

De esta manera, el artículo 13 LCSP dice:

1. Son contratos de obras aquellos que tienen por objeto uno de los siguientes:

a) La ejecución de una obra, aislada o conjuntamente con la redacción del proyecto, o la realización de alguno de los trabajos enumerados en el Anexo I.

b) La realización, por cualquier medio, de una obra que cumpla los requisitos fijados por la entidad del sector público contratante que ejerza una influencia decisiva en el tipo o el proyecto de la obra.

2. Por "obra" se entenderá el resultado de un conjunto de trabajos de construcción o de ingeniería civil, destinado a cumplir por sí mismo una función económica o técnica, que tenga por objeto un bien inmueble.

Abeledo-Perrot, 2010, 317.

7 Este criterio fue tempranamente sostenido en Chile por la Contraloría General de la República. Véase Dictamen 32.795/1996.

8 Dromi, R. Derecho administrativo. Buenos Aires: Ciudad Argentina, 2001, 510.

9 Rufián Lizana. Manual de concesiones de obras públicas, cit., 32.

10 Ley 9/2017, del 8 de noviembre, de Contratos del Sector Público, por la que se transponen al ordenamiento jurídico español las directivas del Parlamento Europeo y del Consejo 2014/23/UE y 2014/24/UE, del 26 de febrero de 2014, Boletín Oficial del Estado, 9 de noviembre de 2017. 
También se considerará “obra” la realización de trabajos que modifiquen la forma o sustancia del terreno o de su vuelo, o de mejora del medio físico o natural.

En seguida, el artículo 14 se refiere al contrato de concesión de obras en los siguientes términos:

1. La concesión de obras es un contrato que tiene por objeto la realización por el concesionario de algunas de las prestaciones a que se refiere el artículo anterior, incluidas las de restauración y reparación de construcciones existentes, así como la conservación y mantenimiento de los elementos construidos, y en el que la contraprestación a favor de aquel consiste, o bien únicamente en el derecho a explotar la obra en el sentido del apartado cuarto siguiente, o bien en dicho derecho acompañado del de percibir un precio. [Cursivas fuera de texto].

Como puede advertirse, el artículo 14.1, para definir la concesión de obra pública, razona sobre la base de que ella tiene por objeto la realización de alguna de las prestaciones del artículo 13, esto es, de alguna de las prestaciones del contrato de obras. A ello se debe añadir la conservación y mantenimiento de los elementos construidos, actividades imprescindibles para que el concesionario pueda ejercitar su derecho de explotación económica, que corresponde a la contraprestación a su favor (sin perjuicio, como establece la norma, de su eventual derecho a la percepción de un precio).

La situación en el derecho italiano es idéntica. En efecto, el Decreto Legislativo del 18 de abril de 2016, n. ${ }^{\circ}$ 50, Codice dei contratti pubblici, también define al contrato de concesión a partir de las prestaciones propias del contrato de obras. De esta manera, el artículo 3, apartado 1, letra 11) sobre el contrato de obras públicas (contratto di appalto pubblico di lavori), establece que ellos son:

Contratos estipulados por escrito entre uno o más entes contratantes y uno o más operadores económicos que tienen por objeto: 1) la ejecución de trabajos relativos a alguna de las actividades del anexo I; 2) la ejecución o bien el diseño ejecutivo y ejecución de una obra; 3 ) la realización, por cualquier medio, de una obra correspondiente a las exigencias especificadas por la administración o ente adjudicador que ejercita una influencia determinante sobre el tipo o sobre el diseño de la obra ${ }^{11}$.

Por su lado, el mismo artículo 3 , inciso 1, letra uu) define el contrato de concesión de obras públicas (concessione di lavori pubblici) del modo siguiente:

11 Trad. libre. 
Contrato a título oneroso estipulado por escrito en virtud del cual uno o más entes contratantes confían la ejecución de trabajos, o bien el diseño ejecutivo y ejecución, o bien el diseño definitivo, el diseño ejecutivo y la ejecución de trabajos, a uno o más operadores económicos reconociendo a título de contraprestación únicamente el derecho de gestión de las obras objeto del contrato, o tal derecho acompañado de un precio, asumiendo el concesionario el riesgo operacional ligado a la operación de la obra ${ }^{12}$. [Cursiva fuera de texto].

Por su parte, el derecho colombiano se coloca en la misma senda ya que los numerales $1 .^{\circ}$ y $4 .^{\circ}$ del artículo 32 de la Ley 80 de 1993 establecen, respectivamente:

\section{1. ${ }^{\circ}$ Contrato de obra}

Son contratos de obra los que celebren las entidades estatales para la construcción, mantenimiento, instalación y, en general, para la realización de cualquier otro trabajo material sobre bienes inmuebles, cualquiera que sea la modalidad de ejecución y pago...

\section{4. ${ }^{\circ}$ Contrato de concesión}

Son contratos de concesión los que celebran las entidades estatales con el objeto de otorgar a una persona llamada concesionario [...] la construcción, explotación o conservación total o parcial, de una obra o bien destinados al servicio o uso público, así como todas aquellas actividades necesarias para la adecuada prestación o funcionamiento de la obra o servicio por cuenta y riesgo del concesionario y bajo la vigilancia y control de la entidad concedente, a cambio de una remuneración que puede consistir en derechos, tarifas, tasas, valorización, o en la participación que se le otorgue en la explotación del bien, o en una suma periódica, única o porcentual y, en general, en cualquier otra modalidad de contraprestación que las partes acuerden.

Todas estas normas no son sino reflejo de que el contrato de obras y el de concesión de obras tienen un objeto similar - la ejecución de una obra pública- y que se diferencian en la modalidad que asume la contraprestación a favor del contratista: en aquel, esta contraprestación es pagada y financiada por el Estado; en este, tal contraprestación se traduce en el reconocimiento de un "derecho de explotación" de la obra. Esto, en principio, significa que no será el Estado quien pague la remuneración del concesionario, sino los usuarios de la obra pública realizada ${ }^{13}$.

12 Ibíd.

13 Menéndez García, P. y Fernández Acevedo, M. Análisis histórico-jurídico de la concesión de obra pública. En MenÉndez Menéndez, A. (ed.), Instrumentos españoles de colabo- 
Como ya se dijo, la forma en la cual el contratista obtendrá el pago por las obras que ejecuta incide decisivamente en la fórmula de financiamiento de las obras. Este financiamiento, en el caso del contrato de obra pública, proviene de pagos directos y periódicos del Estado hacia el contratista privado durante la ejecución de los trabajos, vale decir, se trata de financiación presupuestaria. Como indica Mairal, "en la obra pública, el Estado paga el costo de la obra con sus recursos generales, provenientes de impuestos o del crédito público" ${ }^{14}$. En cambio, en el contrato de concesión dicha financiación proviene del concesionario, quien obtendrá su remuneración de los cobros que haga por los servicios que preste la infraestructura ejecutada ${ }^{15}$. Esta diferencia es de fundamental importancia a la hora de explicar la racionalidad de este contrato.

En efecto, de cuanto se ha dicho no debe concluirse que, dado que los contratos de obras públicas y los contratos de concesión de obras públicas tienen un objeto similar (la construcción de una obra pública), ellos deban ser considerados contratos que admitan una misma regulación. El diferente modo de financiamiento de la obra y de cumplimiento de la obligación del Estado deben traducirse en una marcada diferencia en la formulación de los contratos, no solamente en lo que dice relación con la fase de cumplimiento de las obligaciones sino, también, en la fase previa de planeación de la infraestructura (que, por de pronto, debe ser capaz de generar suficientes ingresos para pagar la inversión de capital realizada por el concesionario).

En resumen, puede afirmarse que junto con la fundamental similitud que existe entre el contrato de obras y el contrato de concesión en lo que concierne a su objeto - la construcción de una infraestructura-, las particularidades de este último contrato tienen su origen en el hecho de que la realización de la obra no es pagada directamente por el Estado, sino que dichos ingresos derivan de la explotación que se permite al contratista concesionario durante el período en el cual se extienda la concesión.

ración público-privada: el contrato de concesión de obras públicas. $2 .{ }^{a}$ Cizur-Menor: Civitas, 2010, 99: "La remuneración [es] una nota muy significativa del sistema concesional, toda vez que la concesión se ha configurado históricamente [...] como una fórmula de financiación de obras públicas (lo que, además, permite distinguirla del contrato de obras). La obra debe ser susceptible, en efecto, de proporcionar al concesionario un rendimiento para que su financiación quede al margen, en buena parte al menos, de los presupuestos públicos". En igual sentido, García Alcorta, J. La ejecución de las obras. En Menéndez Menéndez, A. (ed.), Instrumentos españoles de colaboración público-privada: el contrato de concesión de obras públicas. 2. ed. Cizur-Menor: Civitas, 2010, 178, quien recuerda la "identidad sustancial en cuanto a lo que se refiere a la ejecución de las obras" entre el contrato de obras y la concesión.

14 MaIRAL, H.A. Los riesgos en la financiación privada de proyectos públicos. En Revista de Derecho Administrativo, PUCP. Vol. 13, 2013, 206.

15 Rufí́n Lizana. Manual de concesiones de obras públicas, cit., 22: la "diferencia fundamental [entre ambos contratos] radica entonces en que el financiamiento de la obra se hace por medio del usuario de la misma que se coloca en el lugar del contribuyente que financia los impuestos generales". 
Ahora bien, la modalidad de pago al concesionario dependerá del tipo de infraestructura que se realice y del servicio que ella se encuentre destinada a prestar. Aquí cobra importancia la distinción ya formulada entre obras de uso público y obras de utilidad pública. En relación con las primeras, puede decirse que se trata de obras públicas cuyo destino es que sean utilizadas por la población en un régimen de igualdad y libertad de acceso, como en el caso de una autopista o un aeropuerto. En relación con las segundas, se trata de infraestructuras que se destinan al uso de la misma Administración Pública para que sea ella quien, a su vez, preste un servicio público, como ocurre con un hospital, un centro penitenciario o un edificio de oficinas públicas. La fase de explotación de esta última forma de concesión importa la prestación de servicios notablemente más complejos por parte del concesionario, lo que trae consecuencias relevantes en la regulación jurídica del contrato.

Esta distinción resulta esencial para una acabada comprensión de la evolución que ha vivido la regulación del contrato de concesión de obra pública en el ordenamiento jurídico chileno y su transformación en lo que la legislación y doctrina extranjeras denominan "asociación público-privada".

Si bien es cierto, como se ha visto más arriba, que no es posible encontrar en la legislación chilena una noción preceptiva sobre la concesión de obra pública, las modificaciones que se han introducido a la Ley de Concesiones de Obras Públicas hacen posible sostener que la disciplina legislativa del contrato ha evolucionado en una dirección tal que admite calificar algunas formas de concesiones como "asociaciones público-privadas"16.

En efecto, como lo sostiene el Ministerio de Obras Públicas, las modificaciones introducidas por la Ley 20.410 a la Ley de Concesiones tuvieron por "objeto permitir el buen desarrollo de proyectos de complejidad creciente, donde los aspectos de estándares y calidad de servicio tuvieran mayor preeminencia" 17 . Tales modificaciones se ven reflejadas en la ampliación de la noción de "obra pública fiscal", esto es, del objeto principal del contrato de concesión.

En efecto, hasta la aprobación de la Ley 20.410, la "obra pública fiscal" era definida por el artículo 38 de la Ley de Concesiones en los siguientes

16 Cabe considerar que la Ley 21.044, del 15 de noviembre de 2017, introdujo modificaciones en la Ley Orgánica del Ministerio de Obras Públicas, creando la Dirección General de Concesiones de Obras Públicas. En el nuevo artículo 22 ter, letra f, de la ley, referido a las facultades del Director General de Concesiones de Obras Públicas de establece que, entre las atribuciones y funciones del Director, se encuentra la de "fomentar, promover y difundir ante inversionistas públicos o privados, nacionales o extranjeros, la asociación público-privada en materia de infraestructura, en coordinación con las demás instituciones competentes en esta materia". Por tanto, a partir de la entrada en vigor de esta norma legal, la expresión "asociación público-privada" se ha incorporado al lenguaje legislativo, dejando con ello de ser una expresión únicamente política.

17 Ministerio de Obras Públicas. Concesiones de obras públicas en Chile: 20 años. Santiago: MOP, 2016, 49. 
términos: "Para los efectos de esta ley, se entenderá por obra pública fiscal a cualquier bien inmueble construido, reparado o conservado a cambio de la concesión temporal de su explotación, o sobre bienes nacionales de uso público o fiscales destinados a desarrollar áreas de servicio".

La Ley 20.410 modificó esta norma, que pasó a ser el artículo 39, en el sentido de que por obra pública fiscal se debe entender "cualquier bien inmueble construido, reparado o conservado a cambio de la concesión temporal de su explotación o sobre bienes nacionales de uso público o fiscales destinados al desarrollo de áreas de servicio, a la provisión de equipamiento o a la prestación de servicios asociados" (cursiva fuera de texto).

Como puede advertirse, la norma introducida en 2010 permite que el objeto de las obligaciones del concesionario sea más amplio que la sola "construcción, reparación o conservación" de una obra de infraestructura, extendiéndose a la "provisión de equipamiento o a la prestación de servicios asociados". En virtud de esta modificación legislativa el objeto de la concesión se ha visto ampliado, y con ello se ha incrementado la variedad de proyectos de infraestructura susceptibles de ser ejecutados en virtud de este contrato.

En efecto, hasta la reforma de la Ley 20.410, como se ha dicho, la Administración se encontraba limitada por el texto legal a la licitación de contratos de concesión que requirieran únicamente la "construcción, reparación o conservación" de una infraestructura, y las actividades durante la fase de explotación se encontraban restringidas al mantenimiento de la infraestructura realizada. La reforma de 2010 incorporó a la noción de obra pública la "provisión de equipamiento y la prestación de servicios asociados" como parte de las posibles obligaciones del concesionario. Con esto la ley hizo posible la concesión de una amplia variedad de edificaciones que requieren, precisamente, de la "provisión de equipamiento o prestación de servicios accesorios" $\mathrm{y}$, por ende, del desarrollo de una actividad más compleja y heterogénea por parte del concesionario, que no se encontrará circunscrita al mantenimiento de la infraestructura, sino que deberá extenderse a la prestación de servicios relacionados con la naturaleza y finalidad de la edificación ejecutada y por los cuales, naturalmente, percibirá una remuneración. Es también en este punto que la modificación demuestra su significativa relevancia: los pagos que reciba el concesionario durante la fase de explotación de la concesión serán realizados por el mismo ente concedente y no por el público usuario de la obra ${ }^{18}$.

18 Ramírez Arrayas, J. A. Concesiones de obras públicas. Análisis de la institucionalidad chilena. Santiago: Abeledo-Perrot, 2010, 35, sostiene que "la reforma legal [de la Ley 20.410 de 2010] ha incorporado dentro del marco regulatorio de la ley de concesiones, la provisión de equipamiento y la prestación de servicios asociados, materias que no estaban expresamente consideradas en la reglamentación anterior. La introducción de estas materias facultará al MOP a conceder, conjunta o separadamente, la realización de infraestructura pública, la prestación de otros servicios y la provisión de equipamiento, permitiendo al sistema enfrentar de mejor forma 
La ampliación del objeto del contrato que permite concesiones "de complejidad creciente" ${ }^{19}$ demanda del Estado, durante la fase de explotación de la concesión, una mejor capacidad para controlar la calidad de los servicios prestados por el concesionario. El ejemplo paradigmático de este tipo de concesiones lo encontramos en la concesión de infraestructura hospitalaria. En ella, junto con la construcción o recalificación del edificio que ocupará el recinto hospitalario, el concesionario adquiere la obligación de prestar una serie de servicios que, si bien no tienen carácter sanitario, son fundamentales para la prestación del servicio público sanitario por parte del Estado.

La considerable mayor complejidad de las concesiones de esta clase de infraestructura se advierte fácilmente al comparar los decretos de adjudicación de una concesión de infraestructura vial y de una concesión de infraestructura hospitalaria. En la primera, el decreto de adjudicación de la licitación -que en la legislación chilena cumple la función de contrato de concesión- se limita a establecer como objeto de las obligaciones del concesionario unas pocas prestaciones (básicamente, la construcción de la obra y el mantenimiento de la misma durante la fase de explotación); en la segunda, la actividad que debe desarrollar el concesionario es mayor no solo en número de operaciones sino, especialmente, en cuanto a la complejidad de las mismas: servicios de mantenimiento de variados componentes, sustitución de equipamiento médico y no médico, alimentación, lavandería, vigilancia, administración de aparcaderos, limpieza de las instalaciones, etc. ${ }^{20}$.

la concesión de proyectos de mayor complejidad, como lo son, por ejemplo, la construcción y operación en su caso de recintos carcelarios, hospitalarios y establecimientos educacionales".

19 Ministerio de Obras Públicas. Concesiones de obras públicas en Chile, cit., 49.

20 A continuación se transcriben las cláusulas relativas a las prestaciones del concesionario de dos decretos de adjudicación. El primero, el D.S. mop 1253/2003, publicado en el Diario Oficial del 7 de enero de 2004, adjudicó la concesión de la obra pública fiscal denominada "Acceso Nor-Oriente a Santiago", una autopista de peaje, y establece que "el Concesionario construirá, conservará y explotará las obras que se indican en las Bases de Licitación, correspondientes al nuevo trazado vial que se inicia en el Enlace Centenario (sector Puente Centenario), en el límite de las Comunas de Vitacura y Huechuraba, conectando con las vías Costanera Norte y Av. Américo Vespucio que confluyen en el sector.Éste continúa hacia el Norte a través de un sistema de viaductos y túneles para cruzar la cadena montañosa de los cerros La Pirámide, Manquehue y Montegordo hasta llegar a la zona del valle de la comuna de Colina, donde el trazado toma dirección en sentido poniente cruzando la Ruta 57 Ch hasta conectarse con la Ruta 5 Norte, aproximadamente en el kilómetro 18,3 de esta vía. La longitud aproximada de esta nueva vía es de 21,5 kilómetros, considerando dobles calzadas de dos pistas cada una, ocho túneles, cinco enlaces, atraviesos, dos pasarelas peatonales, tres pasos interprediales, sectores con calles de servicios, etc.". El segundo corresponde al D.S. mop 141/2013, publicado en el Diario Oficial del 21 de junio de 2013, por medio del cual se adjudicó el contrato de concesión para la ejecución, reparación, conservación y explotación de la obra pública fiscal denominada "Hospital de Antofagasta". Este decreto establece, sin perjuicio de la construcción del edificio del hospital, que durante la etapa de explotación de la obra, de acuerdo a lo dispuesto en el artículo 1.10 de las Bases de Licitación, la sociedad concesionaria está obligada a prestar los servicios indicados en el artículo 2.6 de las Bases de Licitación, en las condiciones establecidas en el Anexo B "Etapa 
Como ya se anticipó, la contraprestación por este tipo de prestaciones en infraestructuras de utilidad pública no puede ser pagada de la misma manera que los servicios prestados por una infraestructura de uso público. En este último tipo de obras es el usuario quien pagará por la utilización de la obra construida por el concesionario. El ejemplo más claro lo ofrece la infraestructura vial: en la medida que el usuario transite y haga uso de ella, deberá pagar una tarifa o peaje. El cobro y recolección de dicha tarifa o peaje, durante la fase de explotación de la concesión, debería ser suficiente para amortizar el costo de construcción y de mantenimiento de la obra, así como para permitir al concesionario obtener la rentabilidad correspondiente ${ }^{21}$.

de Explotación. Servicios Básicos, Especiales Obligatorios y Complementarios" de dichas Bases, los que se indican a continuación: a) servicios básicos: servicios no clínicos de apoyo (aseo y limpieza general, gestión integral de residuos hospitalarios, control sanitario de vectores, gestión de ropería y guardarropía, alimentación de pacientes y funcionarios); mantenimiento y operación de la infraestructura, instalaciones, equipamiento industrial y mobiliario asociado a la infraestructura; administración y mantenimiento de mobiliario no clínico; adquisición y reposición de mobiliario no clínico; b) servicios especiales obligatorios (cafetería, seguridad y vigilancia, estacionamiento de funcionarios y visitas, administración y mantenimiento de equipamiento médico y mobiliario clínico, adquisición y reposición de equipamiento médico y mobiliario clínico, servicio de infraestructura tecnológica) y c) servicios complementarios opcionales (alimentación a público en general, estacionamientos para público en general, instalación y explotación de máquinas dispensadoras, área multiservicios -óptica, artículos para enfermos, fotocopias, cajeros automáticos, florerías, cyber café, etc.-).

21 El uso del condicional "debería" es obligatorio. La concesión lleva envuelta la incertidumbre del éxito comercial de la explotación de la infraestructura. El riesgo propio de la fase de explotación (como los riesgos de demanda y de disponibilidad) es un elemento que las legislaciones española, italiana y colombiana consideran al momento de definir la concesión y las asociaciones público-privadas, de suerte que si dicho riesgo de fracaso económico no se encuentra presente, el contrato dejará de ser considerado una concesión y pasará a entenderse como un contrato de obras u otra figura análoga. Sobre el carácter central de la asunción de los riesgos por parte del concesionario para la comprensión de la concesión en el derecho europeo, véase Loo GuTIÉRREz. La distribución de los riesgos en el contrato de concesión de obra pública, cit., 200; Lazo Vitoria, X. El futuro del mercado concesional. En Revista CEF Legal. Vol. 154, 2013, 137, y SAnz Gandasegui, F. El concepto del contrato de concesión de obras públicas. En Menéndez Menéndez, A. (ed.), Instrumentos españoles de colaboración público-privada: el contrato de concesión de obras públicas. 2. ${ }^{\text {a }}$ ed. Cizur-Menor: Civitas, 2010, 129-130. En la legislación colombiana, el artículo 4..$^{\circ}$, parágrafo $3 .^{\circ}$, de la Ley 1508 de 2012 hace explícita referencia a la eficiente asignación de riesgos como elemento de principio de este tipo de esquemas de vinculación de capital privado; y el artículo 32, numeral 4, de la Ley 80 de 1993 hace lo propio al establecer que las actividades del contrato se realizan "por cuenta y riesgo del concesionario". Recientemente, con motivo de la adopción de la Ley 9/2017, la doctrina española ha sido generosa en la producción de estudios sobre la noción de riesgo concesional. Véanse Huergo Lora, A. El riesgo operacional en la nueva ley de contratos del sector público. En Documentación Administrativa, nueva época. Vol. 4, 2017, 31; RomÁn MÁrQuEZ, A. El riesgo en las concesiones de obras y servicios públicos. Orígenes, evolución y situación actual en el ordenamiento jurídico comunitario. En Revista Española de Derecho Administrativo. Vol. 182, 2017, 445, y LAzo VitoRia, X. El riesgo operacional, ¿una nueva era para los contratos de concesión? En El Cronista del Estado Social y Democrático de Derecho. Vol. 74, 2018, 62. Esta temática excede el objeto del presente artículo, por lo que no será abordada. 
En este caso se está frente a infraestructuras cuya explotación aparece, de inmediato, como una tarea menos compleja que la operación de un hospital, especialmente si se consideran los "servicios asociados" que demanda este último tipo de obras. En este caso, contrariamente a cuanto parece ser intuitivo en una concesión, esto es, que los pagos que remunerarán al concesionario deben provenir de la población usuaria de la infraestructura, no es -ni puede ser- el usuario del hospital (o de la cárcel, o del edificio de oficinas públicas, etc.) quien paga al concesionario por el uso que haga del mismo. Es por ello que este tipo de infraestructura debe calificarse como de utilidad pública y no como de uso público.

En este tipo de contratos, el sistema de remuneración del concesionario es mucho más complejo y constituye una de las cuestiones más arduas que plantea esta clase de concesiones. Se trata de un conjunto de pagos periódicos de sumas, algunas fijas y otras variables, que el Estado debe realizar al titular de la concesión con el fin de amortizar los costos de construcción (o de recalificación) del inmueble y los servicios que el concesionario desarrolle a favor de la Administración encargada de la prestación del respectivo servicio público. Se trata, en definitiva, de pagos hechos por la Administración por los servicios que recibe del concesionario.

Por ello, un aspecto esencial en este tipo de concesiones es que la remuneración del concesionario se debe encontrar vinculada a los estándares de calidad de los servicios que presta al concedente ${ }^{22}$. Por dicho motivo es necesario que los contratos de concesión establezcan mecanismos de control de los niveles de calidad de servicio que el concedente debe verificar y cuyo cumplimiento se incentiva a través del establecimiento de pagos adicionales a favor del contratista ${ }^{23}$.

22 En efecto, fue precisamente la posibilidad de poner el acento en la calidad del servicio el primer motivo invocado en la iniciativa legislativa que concluyó con la reforma al artículo 38 de la Ley de Concesiones (hoy, art. 39). Véase Mensaje de S.E. la Presidenta de la República en cuya virtud se inició la tramitación de la Ley n. ${ }^{\circ} 20.410$, en Biblioteca del Congreso Nacional. Historia de la Ley n. ${ }^{\circ}$ 20.410. Valparaíso: Biblioteca del Congreso Nacional, 2018, 3.

23 Por ejemplo, el punto 18 del D.S. MOP 141/2013, de adjudicación de la concesión del "Hospital de Antofagasta", dispone que "en conformidad a lo establecido en el artículo 1.10.11 de las Bases de Licitación, se establece un Mecanismo de Determinación de Niveles de Servicio, el cual tiene por finalidad generar incentivos para una adecuada prestación de los servicios, y de ninguna forma constituye un incentivo económico garantizado en el tiempo, en cuanto no se cumplan las condiciones y exigencias establecidas en los artículos 2.6.2.1, 2.6.2.2, 2.6.2.3 y 2.6.2.4 de las Bases de Licitación”. En este sentido, Moraga Klenner. ¿Hace falta una ley de asociaciones público-privadas en Chile?, cit., 118, indica que entre las características de las APP se encuentra el hecho de que cuentan con "estándares precisos de calidad" que se pueden traducir a través de indicadores de suministro. Agregando que "del cumplimiento de estos indicadores depende el pago de los subsidios que tiene derecho a recibir el empresario o la organización privada". 
Como puede apreciarse a primera vista (y lo reconoce el mismo Ministerio de Obras Públicas ${ }^{24}$ ), este tipo de contratos es sustancialmente más complejo de ejecutar y fiscalizar, hasta el punto de que la doctrina más autorizada en materia de concesiones plantea dudas acerca de la pertinencia de realizar este tipo de infraestructura por medio de esta clase de contratos ${ }^{25}$. Se volverá sobre esto más adelante.

Entonces, retomando la cuestión que da título a este apartado, cabe preguntarse: ¿qué son hoy día las concesiones de obra pública en la legislación chilena?

Como se ha podido ver, en Chile, las concesiones de obra pública han vivido una importante evolución desde que su utilización tomó fuerza a comienzos de la década de 1990. En su forma original, las concesiones buscaron (y permitieron) el rápido incremento del stock de infraestructura vial. Es así como el programa de concesiones de obras públicas impulsado por el Ministerio de Obras Públicas chileno se consolidó y logró poner en operación importantes rutas interprovinciales: la ruta Panamericana al norte y al sur de Santiago, las autopistas que unen los puertos de Valparaíso y San Antonio a Santiago, entre otras.

Con la consolidación y el crecimiento del programa de concesiones se hizo necesario emprender proyectos de creciente complejidad desde el punto de vista técnico, pero siempre en el ámbito de la infraestructura vial. De este modo surgieron las concesiones de las autopistas urbanas del Gran Santiago. Se sumaron a ellas otras infraestructuras del sistema de transporte, como los aeropuertos.

Solo a inicios de los años 2000 se comenzaron a desarrollar obras más complejas desde el punto de vista de los servicios que ellas entregan. Así se ejecutaron algunos recintos penitenciarios (Iquique, La Serena, Rancagua) y algunas edificaciones públicas (como el Centro de Justicia de Santiago).

La complejidad de los servicios desarrollados en las infraestructuras ha alcanzado su mayor nivel con las concesiones de recintos hospitalarios (MaipúLa Florida y, luego, Antofagasta, Félix Bulnes y El Salvador-Geriátrico), en los cuales, como ya se ha dicho, junto con la construcción del edificio propiamente tal, el concesionario se obliga a la provisión del equipamiento y a la prestación de numerosos servicios complementarios.

Si observamos la evolución que ha vivido la concesión de obras públicas en Chile, rápidamente reseñada en las líneas anteriores, puede advertirse

24 Véase Ministerio de Obras Públicas. Concesiones de obras públicas en Chile, 131, donde se sostiene que la reforma legal de la Ley 20.410 puso el acento en un "desafío más complejo para la labor de fiscalización [...]. En otras palabras, con la evolución del sistema, no solo aumentaron las tareas en este ámbito, sino también cambió su orientación".

25 Engel, E.; Fischer, R. y Galetovic, A. El programa chileno de concesiones de infraestructura: evaluación, experiencias y perspectivas. En LARRAín, F. y VERGARA, R. (eds.), La transformación económica de Chile. 2. a ed. Santiago: Centro de Estudios Públicos, 2001, 204. 
que ha pasado de ser un mecanismo de construcción de infraestructura de servicio público a ser un medio de producción de servicios para el Estado a través de infraestructuras ${ }^{26}$. Si en un primer momento el acento del proyecto se encontraba puesto en la construcción de una obra pública para que, con su explotación, se prestara un servicio directamente a la colectividad, hoy día la concesión es un mecanismo por medio del cual el Estado adquiere un flujo de servicios para cuyo desarrollo es necesaria la construcción de una infraestructura.

En consecuencia, puede concluirse que en el ordenamiento chileno la concesión de obra pública es un contrato en cuya virtud la Administración del Estado encarga a un tercero la construcción de una obra pública, la cual es remunerada permitiendo su explotación en la prestación de servicios a favor de la población, de la misma Administración Pública o de ambos.

Esta noción de la concesión de obra pública se condice con la conceptualización que la doctrina comparada realiza de los esquemas de financiamiento privado de infraestructuras conocidos como "Private Finance Initiative" (PFI), que es considerado como uno de los primeros programas de "asociaciones público-privadas" implementados a nivel mundial.

Así, por ejemplo, en el Reino Unido se sostiene que esta clase de operaciones consiste en un tipo de provisión de servicios públicos o de contratación gubernamental caracterizado por el hecho que involucra la provisión de bienes de capital por el sector privado cuyo uso, luego, es dado en arrendamiento por el sector privado a las autoridades públicas, o directamente al público o a ambos $^{27}$.

Por su parte, en España, las asociaciones público-privadas han sido bien conceptualizadas señalando que ellas se caracterizan por tres notas fundamentales: primero, la activa participación del contratista privado en la definición del proyecto; segundo, la gestión de la obra pública o del equipamiento público, no directamente para los particulares, sino para la propia Administración, que utiliza la infraestructura como base física de la prestación de servicios

26 Rufián Lizana. Manual de concesiones de obras públicas, cit., 25): "la concesión no aparece ya como una forma de financiar la ejecución de obra pública [...] sino como un intercambio en la persona que presta el servicio público concedido".

27 CANE, P. Administrative law. 5. a ed. Oxford: Oxford University Press, Clarendon Law Series, 2011, 28. El pasaje dice así: "PFI has been described as 'the subset of public service procurement or government contracting which is characterized by the fact that it involves private sector provision of capital assets, the use of which is then, as it were, rented out by the private sector either to the public authorities or directly to the public, or both"'. En igual sentido, DAVIES, A. Accountability. A Public Law Analysis of Government by Contract. Oxford: Oxford University Press, 2001, 5, quien sostiene, además, que en el Reino Unido las directrices sobre formulación de estos contratos establecen que los mismos deben redactarse tomando la perspectiva de la provisión de servicios en lugar de la construcción del inmueble. 
públicos a los ciudadanos; y tercero, la retribución del contratista no es abonada directamente por los usuarios, sino por la propia Administración ${ }^{28}$.

A la luz de lo anterior, el sistema concesional chileno puede ser bien descrito sosteniendo que la creciente complejidad de los proyectos que se encomiendan al sector privado ha transformado la finalidad del contrato de concesión de obra pública. Este ha pasado de ser un contrato de construcción de infraestructura con una modalidad especial de remuneración (el "derecho de explotación") a un contrato de adquisición de servicios por parte del Estado, cuyo desarrollo supone que el concesionario ejecute la obra pública que resulta necesaria para prestar una serie de servicios al concedente. Este tipo de concesión, en Chile, ha pasado a ser una verdadera "asociación públicoprivada" 29 .

Corresponde preguntarse la razón que justifica estos cambios, y la respuesta se logrará indagando en las motivaciones que, tanto en Chile como en el extranjero, se han dado para realizar este tipo de operaciones.

\section{2. ¿POR QUÉ SE UTILIZAN LAS CONCESIONES?}

Desde el punto de vista histórico, las concesiones surgen como mecanismo de financiamiento privado de obras públicas. Nacen, en otras palabras, como una modalidad de desarrollo de infraestructura pública financiada y construida por empresarios privados en virtud de una autorización del Estado que, luego, concede el derecho de cobrar por el uso que la población haga de la obra. La literatura comparada da cuenta de que el modelo de concesiones se utilizaba en Inglaterra ya en los siglos XVIII y XIX para la construcción de caminos y puentes ${ }^{30}$ o el desarrollo de ferrocarriles, el abastecimiento de aguas y la producción de energía eléctrica ${ }^{31}$. Chile no fue ajeno a este proceso histórico. Muestra de ello se encuentra en la Ley del 2 de septiembre de 1835 por medio de la cual se autorizó al Presidente de la República para promover la "construcción de caminos, puentes i canales, concediendo a los empresarios la facultad de cobrar moderados i proporcionados derechos de

28 MAGIDE, M. Instrumentos contractuales de colaboración público-privada para la provisión de infraestructuras públicas en el derecho español. En Revista de Derecho Administrativo, PUCP. Vol. 16, 2016, 130.

29 Valdivia Olivares, J. M. Manual de derecho administrativo. Valencia: Tirant lo Blanch, 2018,313, en el más reciente manual de derecho administrativo publicado en Chile, al definir concesión de obra pública pone el acento en la provisión del servicio público antes que en la construcción de la obra, cuestión que demuestra el cambio de acento en la comprensión de este contrato que comienza a advertirse a nivel doctrinal.

30 Yescombe, E. R. Public-Private Partnerships: Principles of Policy and Finance. Oxford: Butterworth-Heinemann, 2007, 5.

31 Dorrego de Carlos, A. y Martínez Vásquez, F. La colaboración público-privada. En Dorrego de Carlos, A. y Martínez Vásquez, F. (eds.), La colaboración público-privada en la Ley de Contratos del Sector Público. Madrid: La Ley, 2009, 37. 
peaje, pontazgo y navegación, o haciéndolos cobrar por ajentes públicos, con el único i exclusivo objeto de indemnizar a dichos empresarios" $" 32$.

Como puede advertirse, el desarrollo inicial de las concesiones se explica en la necesidad de los Estados de contar con infraestructuras cuya ejecución no podían financiar. Por ello, ante la imposibilidad de acometer la construcción de redes viales, ferroviarias o sanitarias, los Estados autorizaron la intervención de los privados en la financiación y realización de dichas infraestructuras, las cuales serían luego explotadas por su promotor, permitiéndosele el cobro de un peaje o tasa a sus usuarios.

Este mecanismo de financiación de infraestructuras fue abandonado durante el siglo Xx, luego de que los Estados nacionales europeos asumieran la tarea de prestación directa de servicios públicos y desplazaran la participación del sector privado, tanto en la construcción de infraestructura como en la prestación de servicios a la población ${ }^{33}$. Es así que el siglo xx puede ser calificado como el siglo del servicio público y, por lo mismo, como el siglo de la gestión estatal del patrimonio infraestructural de los Estados.

Sin embargo, desde los años ochenta del siglo xx se asiste a un renacimiento de la concesión ${ }^{34}$. Este renacer se justifica, sin embargo, solo parcialmente en las razones que explicaron el surgimiento de este modo de realización de infraestructuras.

En efecto, si se revisa la literatura puede advertirse que existe fundamental acuerdo en que el resurgimiento de las concesiones (como manifestación de una actitud de repliegue del Estado que se enmarca dentro de un proceso más general de "privatización" de su actividad) se verifica, inicialmente, en el Reino Unido durante el gobierno de la primera ministra Margaret Thatcher.

32 Artículo 1. ${ }^{\circ}$ de la Ley sin número del 2 de septiembre de 1835. Disponible en: leychile. cl bajo el ID de norma n. ${ }^{\circ} 1105557$. Por su parte, Rufián Lizana. Manual de concesiones de obras públicas, cit., 25), reconoce la finalidad de captación de recursos ya en la Ley 15.840 de 1964, sobre organización y atribuciones del Ministerio de Obras Públicas.

33 Loo Gutiérrez, M. Las asociaciones público-privadas en la Unión Europea: elementos para un análisis sobre la concesión de obra pública en Chile. En Revista de Derecho de la Pontificia Universidad Católica de Valparaíso. Vol. 45, 2015, 326; Grimsey, D. y Lewis, K. M. Public-Private Partnerships. The Worldwide Revolution in Infrastructure Provision and Project Finance. Cheltenham-Northhampton (Mass): Edward Elgar, 2004, 19. De igual manera, MoRAGA KLENNER. La actividad formal de la Administración del Estado, cit., 319, señala que, "avanzando el siglo xx, los sistemas que propendían a la construcción directa de las obras públicas de diverso tipo por los privados bajo el régimen jurídico de permiso o concesión de obras públicas cayeron en desuso por razones económicas, políticas y, finalmente, ideológicas. El Estado quedó como único ente encargado de la provisión y operación de las diversas infraestructuras públicas".

34 Grimsey y LeWIs. Public-Private Partnerships, cit., 71, señalan que, habiendo analizado "the changing involvement of the private sector in infrastructure investment in Britain, the United States and France [,] in all three countries, and in others as well, the dominant public sector role in producing, delivering and financing infrastructure services, which held sway for most of the twentieth century, has given way in recent years to experimentation with a variety of means of engaging private sector resources for infrastructure". 
En dichos años se comenzó a recurrir a empresas privadas para construir infraestructura y operar servicios públicos, llevándose también adelante un programa de enajenación de los activos de numerosas empresas públicas (telefonía, gas, agua, electricidad, ferrocarriles) ${ }^{35}$. Le siguieron países de todo el mundo y, especialmente, países sudamericanos ${ }^{36}$.

¿Cómo explica la literatura este renovado interés por la participación del sector privado en cuestiones que, hasta ese momento, eran llevadas adelante por el sector público? Se sostiene que la política pública formulada por el gobierno Thatcher buscaba incrementar la eficiencia de los servicios públicos a través de la externalización de su prestación en empresas del sector privado ("contracting-out"). La literatura reconoce en dicha política motivaciones ideológicas, vinculadas al neoliberalismo económico que por esos años iba tomando fuerza y que se tradujeron en una explícita desconfianza institucional hacia la prestación de servicios públicos por parte del Estado ${ }^{37}$. De este modo se ejecutaron una serie de iniciativas que se movieron en dos direcciones complementarias. Por un lado, se buscó recurrir "al capital privado para la realización de las actuaciones públicas", por otro, a imitar en el sector público el modo de administración de las empresas privadas con el objetivo de incrementar su eficiencia: este fue el denominado 'New Public Management"' 38 .

Estas políticas que buscaban aumentar la eficiencia del aparato estatal se hicieron atractivas en el continente europeo, despertando el interés de sus órganos políticos supranacionales. En efecto, la implementación de este tipo de medidas por parte de la Unión Europea fue antecedida por la adopción de algunas decisiones que obligaron a los Estados miembros a revisar sus niveles de endeudamiento y déficit público. Sobre el particular es necesario recordar que, a partir de la celebración del denominado "Pacto sobre Estabilidad y Crecimiento" (Resolución del Consejo de Europa, Ámsterdam, 17 de junio de 1997), los órganos comunitarios manifestaron sin medias tintas su compromiso con la contención del endeudamiento y del déficit públicos. Esta política se tradujo en el artículo 126.1 del Tratado sobre el Funciona-

35 Dewulf, G.; Blanken, A. y Bult-Spiering, M. Strategic Issues in Public-Private Partnerships. 2. ${ }^{\text {a }}$ ed. Oxford: Wiley-Blackwell, 2012, 50, afirman que el sistema inglés de concesiones, denominado PFI, "coincides with the upsurge in privatisation. The introduction of privatisation and PFI represented a cultural turning point".

36 Gómez-IbÁÑez, J. A. Regulating Infrastructures: Monopoly, Contracts and Discretion. Cambridge (Mass.): Harvard University Press, 2003, 1; NIETO GARRIDO, E. La financiación privada de obras y servicios públicos en el Reino Unido (The private finance initiative a public-private partnerships). En Revista de Administración Pública. Vol. 164, 2004, 389.

37 DAVIES. Accountability, cit., 3.

38 GonZÁlez García, J. V. Colaboración público-privada e infraestructuras de transporte. Madrid: Marcial Pons, 2010, 16. Sobre el New Public Management, véase NiETo GarRido, E. El new public management y el Gobierno a través de contratos en el Reino Unido. En Revista de Administración Pública. Vol. 162, 2003, 391. 
miento de la Unión Europea que estableció que "los Estados miembros [de la Unión Europea] evitarán déficits públicos excesivos".

Por otra parte, la Unión Europea impulsó una agresiva política de construcción de infraestructuras que se ponía en tensión con la finalidad de reducción del gasto público. A partir de la década de 2000, los órganos políticos europeos insistieron en la necesidad económica y social de contar con una red de transportes transeuropea que permitiera el desarrollo del comercio y facilitara la actuación del principio de "libre circulación" de bienes, servicios y personas que había inspirado el establecimiento de la Comunidad Económica Europea en 1957. Para ejecutar dichas infraestructuras y, al mismo tiempo, evitar endeudamiento público excesivo se decidió incentivar la participación de capitales privados que financiaran su construcción ${ }^{39}$.

Es en este contexto dominado por dos grandes finalidades políticas (limitación del endeudamiento público y promoción del desarrollo de grandes obras públicas) que, a partir de 2004, la Unión Europea llevó adelante una serie de medidas que buscaron dar un marco normativo apropiado a la participación privada en la ejecución de infraestructuras. Entre las medidas antes mencionadas, junto con la expedición de las directivas sobre contratos públicos de marzo de 2004, se cuenta la emanación, en abril del mismo año, del "Libro Verde sobre la colaboración público-privada y el derecho comunitario en materia de contratación pública y concesiones" ${ }^{40}$ y, también, de una decisión de Eurostat, la oficina de estadísticas europea, sobre el tratamiento que debía darse en la contabilidad pública a los acuerdos de "asociación público-privada" ${ }^{41}$. Ambas medidas fueron un fuerte aliciente para que los Estados miembros de la Unión Europea introdujeran normas sobre un nuevo contrato administrativo que, en general, fue denominado "contrato de colaboración público-privada". Así, por ejemplo, y sin estar explícitamente obligados a ello por el derecho supranacional, tanto España como Italia adoptaron normas sobre el contrato de colaboración público-privada en las leyes de transposición de las directivas sobre contratos públicos del año 2004. Italia recogió una breve regulación en el Codice dei contratti pubblici (Decreto Legislativo 163/2006, hoy Decreto Legislativo 50/2016) y España desarrolló una disciplina del contrato más detallada en la Ley de Contratos del Sector Público (Ley 30/2007, hoy Ley 9/2017) ${ }^{42}$.

39 Comisión de las Comunidades Europeas. Desarrollo de la Red Transeuropea de Transporte. Financiaciones innovadoras. Interoperabilidad del telepeaje. сом (2003) 132 Final. 23 de abril de 2003, 1.

40 Comisión de las Comunidades Europeas. Libro Verde sobre la colaboración públicoprivada y el derecho comunitario en materia de contratación pública y concesiones, Сом (2004) 327 Final. 2004, 1.

41 Eurostat. Long Term Contracts between Government Units and Non-Government Partners (Public-Private Partnerships). 2004, 1.

42 Para un análisis de las normas italiana de 2006 y española de 2007, véase Loo GuTiÉRREZ, M. I principi di sussidiarietà e solidarietà nel partenariato pubblico-privato contrattuale. Roma: Aracne, 2014, III. Para la evolución del contrato en España, especialmente como consecuencia de 
Las medidas adoptadas por Eurostat tuvieron por finalidad primordial dar certeza a las administraciones de los Estados miembros de la Unión acerca del tratamiento contable que se aplicaría a las asociaciones público-privadas y otros acuerdos que conllevaran la financiación del desarrollo de obras públicas y la prestación de servicios públicos por parte del sector privado. De esta forma, se puede afirmar que la Unión Europea adoptó reglas contables para el tratamiento de las inversiones realizadas en el ámbito de contratos que involucraran la participación privada en el desarrollo de infraestructura pública mucho antes que reglas jurídicas sobre el contrato de concesión, de tal manera que hoy, luego de la aprobación de las directivas sobre contratos públicos y concesiones del año 2014 (a que se aludirá en seguida), es posible advertir un esfuerzo por coordinar ambos tipos de reglas ${ }^{43}$.

El desarrollo de esta política tuvo su más relevante expresión legislativa en la aprobación, en febrero de 2014, de las nuevas directivas sobre contratación pública europea, entre las cuales se incluyó, por primera vez, una directiva destinada exclusivamente a la regulación del contrato de concesión (Directiva 2014/23/UE).

Puede observarse que este paquete de medidas normativas tuvo por objetivo principal incentivar a los Estados miembros de la Unión Europea a sustituir la financiación presupuestaria de las infraestructuras públicas por el financiamiento privado de las mismas. Sin embargo, a diferencia de cuanto ocurrió en los orígenes de la concesión, la justificación de esta política se encuentra en la necesidad de disminuir el endeudamiento público de los países de la Unión, no en la incapacidad de sus economías de financiar la construcción de infraestructuras. Con esto se quiere destacar que la política de promoción de las concesiones y de las asociaciones público-privadas en Europa encuentra su motivación en la exigencia de aligerar el peso en la contabilidad fiscal de las inversiones en infraestructura, no en la estrechez financiera de estas economías ${ }^{44}$.

la crisis financiera iniciada el año 2008, véase PALOMAR OLMEDA, A. El contrato de colaboración público-privada. En A. Palomar Olmeda, A. y De Álvaro Montero, Á. (eds.), La colaboración público-privada: análisis avanzado de los problemas prácticos de esta modalidad contractual. Cizur-Menor: Aranzadi, 2011, 85.

43 Román MÁrQuez. El riesgo en las concesiones de obras y servicios públicos, cit., 450.

44 HuERgo LoRA. El riesgo operacional en la nueva ley de contratos del sector público, cit., 43 , sostiene que "no hay que olvidar que en las normas SEC existe un sesgo favorable a admitir la colaboración público-privada, que es una técnica que las instituciones de la UE consideran irrenunciable para la realización de inversiones públicas", y luego, que estas técnicas contables de registro de las inversiones públicas vinculadas a las asociaciones público-privadas son "uno de los principales atractivos para las Administraciones Públicas". En el mismo sentido, véase RomÁn MÁRqueZ $(2017,448)$, quien señala que "a pesar de que la Unión Europea valora positivamente las ventajas que la institución concesional aporta a los Estados miembros, sabe también por experiencia que existe una enorme tentación de que los Estados acudan a esta figura únicamente por ser una forma de transferir sus gastos al sector privado y que no figuren en los pasivos nacionales, sino en los de aquél, y así cumplir los compromisos de consolidación presupuestaria 
Por estas razones, si se mira la experiencia europea de los últimos quince años puede afirmarse que las concesiones y las asociaciones público-privadas encuentran su justificación en la necesidad de mantener una disciplina fiscal que busca limitar el exceso de endeudamiento y de déficit: se trata, como puede apreciarse, de una justificación de naturaleza contable más que estrictamente económic ${ }^{45}$.

Conviene ahora preguntarse qué justificación se ha dado en Chile a las concesiones de obra pública y ver si tales razones se mantienen vigentes luego de las modificaciones introducidas a la Ley de Concesiones por la Ley 20.410 , teniendo especialmente en cuenta la sustantiva variación del objeto del contrato que introdujo la norma referida.

En el sistema chileno, el fuerte impulso político dado a las concesiones de obra pública se ha explicado a partir de dos argumentos. El primero, aportado por la doctrina jurídica, señala que las concesiones de obra pública se justifican porque la Constitución Política de 1980, al haber recogido y consagrado en sus normas el principio de subsidiaridad del Estado, ordenaría que las tareas de satisfacción de intereses generales que puedan ser desarrolladas por los privados en lugar del sector público sean llevadas adelante por ellos.

El segundo argumento, aportado esta vez por los primeros trabajos de los economistas interesados en las concesiones, señala que ellas se justificaron en Chile, simplemente, porque -una vez retomada la institucionalidad de-

vigentes desde el Tratado de Maastricht y acentuados en los últimos tiempos. Este mecanismo de ingeniería contable es perfectamente compatible con el ordenamiento comunitario, pues la Unión Europea no entra a valorar si los Estados miembros recurren a la institución concesional con la finalidad auténtica de mejorar la eficacia y la eficiencia administrativas o simplemente como una fórmula para rebajar el gasto público trasladando el coste de construcción y prestación de determinados servicios al sector privado".

45 Esta utilización de la institución concesional como instrumento que permite ajustes contables puede llevar a que los Estados miembros recurran al contrato con el único objeto de aprovechar sus efectos en la contabilidad pública. Lo anterior ha llevado a que tanto la doctrina española como la italiana sostengan que las administraciones públicas, al momento de recurrir a este tipo de mecanismos de financiación, deben actuar en modo cauteloso. Ello porque, en definitiva, estos contratos resultan más onerosos para las arcas fiscales, de manera que la sola justificación contable resulta insuficiente. En este sentido, véase MACHO Pérez, A. B. y Marco PeÑas, E. El impacto de las colaboraciones público-privadas en los niveles de déficit y deuda públicos: análisis de los criterios de Eurostat. En Revista de Administración Pública. Vol. 194, 2014,38, quienes afirman que "la generalización de este tipo de contratos con el objetivo exclusivamente de atender al cumplimiento de la disciplina presupuestaria puede acabar conllevando no solo la consolidación de los activos y pasivos, sino además otros aspectos negativos, como que la financiación resulte a largo plazo más costosa que la ofrecida por los mecanismos tradicionales y que se merme la credibilidad de los datos estadísticos aportados por el Estado ante las instituciones europeas". Igual advertencia había sido realizada por la doctrina italiana la cual, ya en el año 2011, denunciaba un posible uso indebido de la técnica concesional para fines únicamente contables. Véase, en ese sentido, Cori, R.; Giorgiantonio, C. y PARAdisi, I. Allocazione dei rischi e incentivi per il contraente privato: un' analisi delle convenzioni di project financing in Italia. En Le infrastrutture in Italia: dotazione, programmazione, realizzazione. Roma: Banca d'Italia, 2011, 260. 
mocrática, a fines de los años ochenta del siglo pasado- el Estado carecía de recursos suficientes para enfrentar el desarrollo de infraestructura con la velocidad necesaria para colmar el gran déficit existente en la materia. Se analizarán ambos argumentos separadamente.

La doctrina jurídica chilena ha elaborado justificaciones dogmáticas para fundamentar el sistema de concesiones de obra pública. Es decir, a partir de la interpretación de principios que se encontrarían recogidos en el texto constitucional pretende construir una argumentación que engarce las concesiones a la norma fundamental.

Este ejercicio ha sido realizado, por ejemplo, por Ramírez Arrayás, quien inaugura su monografía sobre la concesión de obra pública sosteniendo que ella "surge de la ingeniería jurídica que trama el Constituyente, asegurando, por una parte, el derecho de los particulares a desarrollar actividades económicas y, por la otra, el deber del Estado de asegurar el bien común". El autor continúa señalando que "el sistema concesional se funda precisamente en permitir que los privados ingresen al diseño, construcción y explotación de bienes públicos, absteniéndose en ciertos casos el Estado -subsidiaridad pasiva- de realizar directamente inversiones en ámbitos que pueden financiar y desarrollar los particulares" 46 .

En la misma línea argumentativa, aunque con peculiar convicción y energía, Aróstica ha sostenido que la adopción de la Ley de Concesiones de 1981 coincidió

... con el concepto de Estado subsidiario que -por aquellos años- comenzaba a tomar cuerpo en nuestro país. El objetivo de la ley [...] se hizo consistir, justamente, en que al Estado ya no le corresponde hacerse cargo de todas las obras públicas requeridas, pues, además de tener que destinar sus recursos a otros proyectos de mayor rentabilidad social, le es imperativo trasladar al sector privado el protagonismo central en cuanto hace al crecimiento económico ${ }^{47}$.

Por su lado, aunque en modo menos explícito, Ponce de León sostiene que en el contexto constitucional chileno, en el cual se encuentra consagrado el principio de subsidiaridad, el Estado ha reducido los mecanismos de intervención directa en la economía, permitiendo que los ciudadanos participen en nuevas actividades económicas con contenido social y público que, hasta la fecha, se incluían en el ámbito del servicio público reservado al Estado $\operatorname{administrador}^{48}$.

46 Ramírez Arrayas. Concesiones de obras públicas, cit., 6-7.

47 Aróstica Maldonado, I. Concesión de obras públicas. Bases del modelo chileno. En Ius Publicum. Vol. 15, 2005, 151; cursiva fuera de texto.

48 PonCE de LeÓn SALUCCI, S. El contrato de concesión de obra pública en la legislación chilena. En Revista de Derecho Público. Vol. 79, 2013, 121. En un sentido similar, aunque 
Como puede apreciarse, una parte de la doctrina jurídica chilena intenta explicar el sistema de concesión de obras públicas a partir del supuesto de que en nuestro orden constitucional regiría un principio que impone u obliga al Estado a dar espacio a la participación del sector privado en aquellos ámbitos en los cuales este puede desarrollar actividades en beneficio de la comunidad; de lo cual se derivaría, por otro lado, una suerte de deber de abstención de la organización estatal en caso de que los particulares se encuentren interesados en participar en una determinada actividad económica a causa, precisamente, de la libertad para el desarrollo de las mismas que la Constitución les garantiza.

Al margen de la discusión sobre la vigencia y alcance del principio de subsidiaridad en nuestro ordenamiento constitucional ${ }^{49}$, cabría preguntarse si esta clase de justificaciones dogmáticas son suficientes para explicar la racionalidad de todas las formas que adopta este contrato. Hay motivo para inclinarse a creer que no.

En efecto, la justificación de la concesión en el principio de subsidiaridad deja al descubierto un déficit de reflexión sobre las características de un sistema de desarrollo de infraestructura basado en relaciones económicas y jurídicas sumamente complejas. Con esto se quiere indicar que la concesión, en su aparente simplicidad como contrato celebrado al amparo del principio de subsidiaridad (esto es, un contrato cuya justificación se encuentra en permitir la participación de privados en la realización de infraestructuras y la prestación de servicios públicos; participación privada que, de acuerdo con la Constitución, debería ser predilecta por sobre la actividad de los órganos estatales), esconde decisiones de política pública que demandan intentar elaborar una justificación más sofisticada, en especial cuando se trata de la concesión de infraestructuras cuya explotación consistirá en la prestación de servicios al Estado.

En efecto, agotadas las infraestructuras cuya construcción a través del sistema de concesiones resulta más "obvia", como lo son aquellas que se desarrollan bajo el esquema de pago por uso de la población (peajes u otras modalidades de recaudación de derechos de uso), cabe preguntarse si el sistema de concesiones en Chile sigue entregando las mejores alternativas para construir aquellas otras obras públicas cuya remuneración no sigue el

enérgico en fundamentar las concesiones únicamente en el principio de subsidiaridad, MoRAGA KLENNER. La actividad formal de la Administración del Estado, cit., 320.

49 Cuestión que se ha intentado abordar en otro lugar: Loo GutiérRez, M. La disciplina constitucional del principio de subsidiariedad en Italia y en Chile. En Revista de Derecho de la Pontificia Universidad Católica de Valparaíso. Vol. 33, 2009, 391, y que ha sido recogida por la doctrina nacional: véase, p. ej., VIERA ÁlvarEZ, C. Libre iniciativa económica y Estado social. Santiago: Legal-Publishing, 2013, 196 y FAúNDEZ-SÁNCHEZ, E. Propuesta de reinterpretación y extensión del principio de subsidiariedad económica hacia la cooperación público-privada en Chile. En Revista digital de Derecho Administrativo. Vol. 15, 2016, 221. 
esquema de pago antes indicado, esto es, de infraestructuras en las cuales la remuneración del concesionario no puede sino provenir del mismo concedente. Es este tipo de infraestructuras aquel que, a partir de la Ley 20.410, se permite concesionar por la legislación sectorial.

En efecto, como se recordó más arriba, a partir de esta ley es posible que el Estado otorgue la concesión de obras en las cuales el concesionario se obliga "a la provisión de equipamiento o a la prestación de servicios asociados", vale decir, infraestructuras cuya realización por medio de concesiones cobra sentido solo si se encomienda al concesionario la provisión de servicios al órgano público concedente. Estos esquemas concesionales no pueden encontrarse justificados únicamente en argumentaciones de orden dogmático y, dado que empeñan cuantiosos recursos del erario por varias décadas, demandan la búsqueda de justificaciones que atiendan a la eficiencia y calidad del servicio público, no solamente a su "anclaje" con principios iusfundamentales, como el principio de subsidiaridad.

Por esta razón es que es necesario recordar las justificaciones del sistema concesional que han elaborado los economistas. Así, por ejemplo, Engel, Fischer y Galetovic, en un artículo del año 2001, llegaban a una conclusión sencilla y desoladora: las concesiones de obra pública encontraban plena justificación en Chile a causa de las evidentes carencias económicas, profesionales y técnicas del país. A inicios de los años noventa, en Chile faltaban recursos financieros, organizativos y humanos para desarrollar infraestructura con la velocidad necesaria para colmar el enorme déficit de inversión en infraestructura básica. Estos autores calculaban que, para hacer frente a dicho déficit, entre 1995 y 2000, habrían sido necesarias inversiones por once mil millones de dólares ${ }^{50}$. En ese contexto, la única posibilidad que tenía el Estado chileno para hacer frente a semejante nivel de inversión era atraer capitales privados e iniciar un agresivo programa de concesiones de obra pública.

Como puede verse, Engel, Fischer y Galetovic, con descarnado pragmatismo, a comienzos de los años 2000, justificaron las concesiones de aquellas obras que era necesario ejecutar en el Chile de mediados de los años noventa en la incapacidad del Estado de hacer frente, con sus limitados recursos, a las ingentes inversiones que eran necesarias para colmar las carencias existentes en la materia.

Sin embargo, el razonamiento desarrollado por los economistas se limita únicamente a las infraestructuras que admiten su pago a través del cobro de peajes a los usuarios, no extendiéndose a las infraestructuras más "complejas" que impiden esta forma de remuneración del concesionario y que, por el contrario, exigen la financiación estatal.

50 Engel, Fischer y Galetovic. El programa chileno de concesiones de infraestructura, cit., 202. 
Esta distinción es la que no se advierte en la justificación "dogmática" aportada por la doctrina jurídica chilena. En otras palabras, al pretender anclar el sistema de concesiones a las normas y principios constitucionales vigentes en Chile (vigentes, al menos, para este sector doctrinal), se intenta justificar una operación jurídica, económica y financiera sin realizar las necesarias diferenciaciones que emanan de la diversa naturaleza que puede presentar el objeto contractual de un contrato de concesión, especialmente luego de la reforma legislativa del año 2010.

En efecto, si bien resulta posible sostener argumentos de orden dogmático para justificar la invitación del Estado a los particulares para "asociarse" en el desarrollo de infraestructura pública, cabe cuestionar que tal fundamento sea suficiente para todo tipos de infraestructuras. El problema, por ende, se presenta al intentar justificaciones dogmáticas para las concesiones de infraestructuras que no pueden ser remuneradas por medio del pago de peajes y que requieren de la financiación estatal a través de subsidios, esto es, aquellas infraestructuras cuya explotación requiere de "la provisión de equipamiento o la prestación de servicios asociados" para su correcta funcionalidad, equipamiento y servicios que serán pagados directamente por el Estado.

Este carácter de cierto tipo de contratos de concesión es correctamente advertido por Flores. En un estudio sobre la naturaleza de las subvenciones y los subsidios en los contratos de concesión de obras públicas, el autor descarta la naturaleza subvencional de estas prestaciones económicas y concluye que "el subsidio convenido constituye la única forma de pago del precio del contrato del Estado hacia el concesionario por los servicios prestados, $v . g r$. , [en] proyectos de concesiones penitenciarias" ${ }^{\prime 1}$. Esta constatación es relevante para el argumento que acá se desarrolla, puesto que siendo el subsidio una verdadera contraprestación del Estado, un precio, es necesaria una fuerte justificación para que el Estado empeñe los recursos necesarios para su pago por varias décadas.

Esto significa, por otro lado, que la literatura nacional, si bien reconoce que ciertas concesiones son íntegramente remuneradas por el Estado, no alcanza a apreciar que, como consecuencia de ello, decae la justificación dogmática de las mismas: el principio de subsidiaridad no basta para justificar este tipo de concesiones y se debe, entonces, mirar el problema desde la perspectiva de la eficiencia económica de esta clase de contratos y preguntarse si la concesión de obra pública puede ser utilizada para la ejecución de cualquier tipo de obra, incluso de aquellas que el Estado financia íntegramente a través de subsidios.

Este problema, en cambio, es perfectamente advertido por los economistas. En una reciente obra, Engel, Fischer y Galetovic resumen sus más de dos

51 Flores Rivas, J. C. Concepto y naturaleza de la subvención en el derecho chileno. El caso de la concesión de obra pública. En Revista de Derecho de la Pontificia Universidad Católica de Valparaíso. Vol. 37, 2011, 356-357, 364. 
décadas de estudios sobre las concesiones y llegan a la siguiente conclusión: la concesión no se justifica para todo tipo de infraestructuras, sino solo para aquellas en las que la participación del privado se traduce en una prestación de servicios públicos económicamente más eficiente para el Estado, y siempre que ese aumento de eficiencia no afecte la calidad del servicio. Tales condiciones, como se analizará en una segunda parte de esta investigación, no se presentan en las concesiones cuyo "derecho de explotación" importa que el Estado adquiera servicios del concesionario.

El razonamiento elaborado por estos autores se desenvuelve como sigue: las concesiones son una buena alternativa cuando la calidad del servicio que presta la infraestructura es fácilmente mensurable y la reducción de los costos de operación del concesionario (esto es, su aumento de eficiencia) no tienen un impacto negativo en la calidad de dichos servicios.

En consecuencia, cuando se trata de infraestructuras destinadas a prestar servicios cuya calidad es susceptible de verse afectada negativamente por la rebaja en sus costos de producción y, al mismo tiempo, son servicios cuya calidad es difícil de mensurar y fiscalizar (como los servicios que se prestan en cárceles y hospitales a internos y pacientes), resulta dudoso que la concesión sea la modalidad de desarrollo de infraestructura pública que garantice la mejor prestación del servicio público. Al respecto, Engel, Fischer y Galetovic afirman:

... la provisión pública es la forma organizacional preferida cuando la calidad es la principal preocupación y no es contratable. [...] Para definir estándares "objetivos" [de calidad] se deben traducir las metas a una escala mensurable. Esto es fácil de hacer con carreteras y puertos donde existe consenso en los estándares de desempeño y se pueden fiscalizar fácilmente, pero puede ser muy difícil (e incluso imposible) cuando los servicios son complejos y las metas ambiguas, como en los casos de educación, salud, cárceles [...]. No es sorprendente que en muchos de estos ámbitos el uso de APP haya sido cuestionado ${ }^{52}$.

Siguiendo entonces este razonamiento, parece ser evidente que las concesiones de obras en las cuales es necesario para el pago del concesionario que este, además, efectúe la "provisión de equipamiento o a la prestación de servicios asociados" deben ser objeto de un análisis cuidadoso especialmente respecto de su capacidad de satisfacer correctamente el interés general que motiva la realización de la obra pública.

La existencia, o inexistencia, de criterios que permitan discernir cuándo se presentan tales condiciones será objeto de una segunda parte de esta investigación.

52 Engel, E.; Fischer, R. y Galetovic, A. Economía de las asociaciones público-privadas. Una guía básica. México: Fondo de Cultura Económica, 2014, 209. 


\section{CONCLUSIONES INTERLOCUTORIAS}

A la luz de cuanto se ha analizado en precedencia es posible alcanzar algunas conclusiones que, sin embargo, tienen el carácter de interlocutorias.

Si en Chile se pregunta qué son las concesiones de obra pública cabe constatar que, a pesar de no existir una definición legal en el sistema jurídico nacional, ellas pueden ser conceptuadas como contratos administrativos en cuya virtud se encarga la construcción de infraestructura al contratistaconcesionario otorgándosele (concediéndosele) un "derecho de explotación" de la obra con el objeto de percibir las tasas o peajes que la población pague por el uso de la misma.

Sin embargo, a partir de la reforma introducida por la Ley 20.410 , de 2010 , este concepto se ha ampliado al incorporarse como posible objeto de la concesión la "provisión de equipamiento y la prestación de servicios asociados", cuestión que ha hecho posible la concesión de infraestructuras que se encuentran destinadas al uso exclusivo de órganos de la Administración y, por ende, cuyo "derecho de explotación” consiste en el pago que estos órganos realicen al concesionario ${ }^{53}$.

Este tipo de operaciones cabe incluirlas dentro de la noción de "asociación público-privada" toda vez que importan la gestión conjunta entre la Administración y el concesionario-contratista de una infraestructura para la prestación de un servicio público. En esto la doctrina internacional se encuentra sustancialmente de acuerdo toda vez que reserva el uso de la expresión "asociación público-privada", oponiéndola a la noción de concesión, para aquellas infraestructuras cuya explotación importa que el Estado adquiera un conjunto de servicios cuyo pago, por el mismo Estado, constituye la contraprestación del "socio" privado ${ }^{54}$.

Además, el término "asociación público-privada", conocido solo a nivel de discurso político en Chile hasta la entrada en vigor de la Ley 21.044, del 15 de noviembre de 2017, ha adquirido dignidad legislativa al encomendarse al nuevo Director General de Concesiones la promoción de este tipo de operaciones (nuevo art. 22 ter, letra f, de la Ley Orgánica del Ministerio de Obras Públicas).

Si atendemos ahora a las razones que se formulan en el derecho comparado y en el derecho chileno para justificar la utilización de este tipo de relaciones contractuales entre la Administración del Estado y el sector privado puede advertirse que, al menos en Europa, el recurso a esta técnica contractual ha adquirido justificaciones relacionadas con el mantenimiento de una con-

53 Flores Rivas. Concepto y naturaleza de la subvención en el derecho chileno, cit., 364.

54 GRIMSEY y LewIs. Public-Private Partnerships, cit., 6: "The essence of a PPP is that the public sector does not buy an asset; it is purchasing a stream of services under specified terms and conditions". 
tabilidad fiscal sana. Ahora, en lo que dice estricta relación con Chile, las justificaciones que ha desarrollado la doctrina jurídica son de naturaleza esencialmente dogmática y pasan por alto la relevancia de las modificaciones introducidas a la Ley de Concesiones por la Ley 20.410.

Esta norma legal ha, literalmente, transformado el contrato de concesión, toda vez que ha ampliado su objeto, permitiendo comprender en él las operaciones que la doctrina y la legislación extranjeras (p. ej., el art. 1. e la Ley 1502 de 2012 colombiana) denominan "asociaciones público-privadas". El contrato de concesión en Chile, a partir del año 2010, ha dejado de ser solo un contrato de provisión de infraestructura y se ha convertido en un contrato de prestación de servicios al Estado a través de obras públicas específicamente construidas para ello ${ }^{55}$. La forma de explotación de este tipo de activos requiere la prestación de servicios más numerosos y más complejos que hacen precisa la fijación de estándares de calidad objetivos, claros y mensurables, cuestión que, como sostiene la doctrina económica ${ }^{56}$, es difícil, si no derechamente imposible, de realizar adecuadamente.

En conclusión, si bien es posible advertir una importante evolución de la legislación chilena en materia de concesiones en una dirección tal que permite a la Administración encomendar la ejecución de obras públicas cuya explotación requiere que el Estado concedente adquiera y pague por los servicios prestados con ella, no resulta evidente cuál es la razón que podría justificar que el Estado opte por este tipo de provisión de infraestructuras y servicios públicos en desmedro del contrato de obras tradicional. La doctrina económica advierte que las características de los servicios prestados en este tipo de contratos son de una complejidad tal que hacen muy difícil fiscalizar la calidad y cantidad en que son prestados, cuestión que amenaza el logro de los objetivos propios de las concesiones.

Por tanto, el próximo paso que deberá darse en esta investigación sobre el régimen jurídico del contrato de concesión es determinar si existen en el derecho comparado y chileno criterios atendibles o mecanismos de evaluación confiables que permitan determinar qué tipo de infraestructura resulta posible desarrollar a través de concesiones. Pero esto será materia de otro trabajo.

\section{REFERENCIAS}

Aróstica Maldonado, I. Concesión de obras públicas. Bases del modelo chileno. En Ius Publicum. Vol. 15, 2005.

Biblioteca del Congreso Nacional. Historia de la Ley $n .{ }^{\circ}$ 20.410. Valparaíso: Biblioteca del Congreso Nacional, 2018.

55 Rufí́n Lizana. Manual de concesiones de obras públicas, cit., 33.

56 Engel, Fischer y Galetovic. Economía de las asociaciones público-privadas, cit., 209. 
Bon, P. El régimen de las concesiones administrativas. En Revista de Derecho Administrativo Económico. Vol. 15, 2005.

Cane, P. Administrative Law. 5. a ed. Oxford: Oxford University Press, Clarendon Law Series, 2011.

Comisión de las Comunidades Europeas. Desarrollo de la Red Transeuropea de Transporte. Financiaciones innovadoras. Interoperabilidad del telepeaje. сом (2003) 132 Final. 23 de abril de 2003.

Comisión de las Comunidades Europeas. Libro Verde sobre la colaboración públicoprivada y el derecho comunitario en materia de contratación pública y concesiones, сом (2004) 327 Final. 2004.

Cori, R.; Giorgiantonio, C. y Paradisi, I. Allocazione dei rischi e incentivi per il contraente privato: un'analisi delle convenzioni di project financing in Italia. En Le infrastrutture in Italia: dotazione, programmazione, realizzazione. Roma: Banca d'Italia, 2011.

Davies, A. Accountability. A Public Law Analysis of Government by Contract. Oxford: Oxford University Press, 2001.

Dewulf, G.; Blanken, A. y Bult-Spiering, M. Strategic Issues in Public-Private Partnerships. 2. ${ }^{\text {a }}$ ed. Oxford: Wiley-Blackwell, 2012.

Dorrego de Carlos, A. y Martínez Vásquez, F. La colaboración público-privada. En DoRrego de Carlos, A. y Martínez VÁsquez, F. (eds.), La colaboración público-privada en la Ley de Contratos del Sector Público. Madrid: La Ley, 2009.

Dromi, R. Derecho administrativo. Buenos Aires: Ciudad Argentina, 2001.

Engel, E.; Fischer, R. y Galetovic, A. El programa chileno de concesiones de infraestructura: evaluación, experiencias y perspectivas. En LARraín, F. y Vergara, R. (eds.), La transformación económica de Chile. 2. ed. Santiago: Centro de Estudios Públicos, 2001.

Engel, E.; Fischer, R. y Galetovic, A. Economía de las asociaciones público-privadas. Una guía básica. México: Fondo de Cultura Económica, 2014.

Eurostat. Long Term Contracts between Government Units and Non-Government Partners (Public-Private Partnerships). 2004.

FAÚNDEZ-SÁnChEz, E. Propuesta de reinterpretación y extensión del principio de subsidiariedad económica hacia la cooperación público-privada en Chile. En Revista digital de Derecho Administrativo. Vol. 15, 2016.

Flores Rivas, J. C. Concepto y naturaleza de la subvención en el derecho chileno. El caso de la concesión de obra pública. En Revista de Derecho de la Pontificia Universidad Católica de Valparaíso. Vol. 37, 2011.

García Alcorta, J. La ejecución de las obras. En Menéndez Menéndez, A. (ed.), Instrumentos españoles de colaboración público-privada: el contrato de concesión de obras públicas. 2. ${ }^{\text {a }}$ ed. Cizur-Menor: Civitas, 2010.

González García, J. V. Colaboración público-privada e infraestructuras de transporte. Madrid: Marcial Pons, 2010. 
Gómez-IbÁÑez, J. A. Regulating Infrastructures: Monopoly, Contracts and Discretion. Cambridge (Mass.): Harvard University Press, 2003.

Grimsey, D. y Lewis, K. M. Public-Private Partnerships. The Worldwide Revolution in Infrastructure Provision and Project Finance. Cheltenham-Northhampton (Mass): Edward Elgar, 2004.

Huergo Lora, A. El riesgo operacional en la nueva ley de contratos del sector público. En Documentación Administrativa, nueva época. Vol. 4, 2017.

Lazo Vitoria, X. El futuro del mercado concesional. En Revista CEF Legal. Vol. 154, 2013.

LAzo VitoRia, X. El riesgo operacional, ¿una nueva era para los contratos de concesión? En El Cronista del Estado Social y Democrático de Derecho. Vol. 74, 2018.

Loo Gutiérrez, M. La disciplina constitucional del principio de subsidiariedad en Italia y en Chile. En Revista de Derecho de la Pontificia Universidad Católica de Valparaíso. Vol. 33, 2009.

Loo Gutiérrez, M. I principi di sussidiarietà e solidarietà nel partenariato pubblicoprivato contrattuale. Roma: Aracne, 2014.

Loo Gutiérrez, M. Las asociaciones público-privadas en la Unión Europea: elementos para un análisis sobre la concesión de obra pública en Chile. En Revista de Derecho de la Pontificia Universidad Católica de Valparaíso. Vol. 45, 2015.

Loo Gutiérrez, M. La distribución de los riesgos en el contrato de concesión de obra pública. En Bermúdez Soto, J. (ed.), Perspectivas para la modernización del derecho de la contratación administrativa. Actas de las XI Jornadas de Derecho Administrativo (2014). Valparaíso: Ediciones Universitarias de Valparaíso, 2016.

Macho Pérez, A. B. y Marco Peñas, E. El impacto de las colaboraciones público-privadas en los niveles de déficit y deuda públicos: análisis de los criterios de Eurostat. En Revista de Administración Pública. Vol. 194, 2014.

MAGide, M. Instrumentos contractuales de colaboración público-privada para la provisión de infraestructuras públicas en el derecho español. En Revista de Derecho Administrativo, PUCP. Vol. 16, 2016.

Mairal, H. A. Los riesgos en la financiación privada de proyectos públicos. En Revista de Derecho Administrativo, PUCP. Vol. 13, 2013.

Menéndez García, P. y Fernández Acevedo, M. Análisis histórico-jurídico de la concesión de obra pública. En Menéndez Menéndez, A. (ed.), Instrumentos españoles de colaboración público-privada: el contrato de concesión de obras públicas. 2 . Cizur-Menor: Civitas, 2010.

Menéndez Menéndez, A. Prefacio. En Menéndez Menéndez, A. (ed.), Instrumentos españoles de colaboración público-privada: el contrato de concesión de obras públicas. 2. ${ }^{\text {a }}$ ed. Cizur-Menor: Civitas, 2010.

Ministerio de Obras Públicas. Concesiones de obras públicas en Chile: 20 años. Santiago: MOP, 2016. 
Moraga Klenner, C. La actividad formal de la Administración del Estado. Santiago: Abeledo-Perrot, 2010.

Moraga Klenner, C. ¿Hace falta una ley de asociaciones público-privadas en Chile? En Benavides, J. L. (ed.), Estudios sobre el régimen jurídico de las asociaciones públicoprivadas. Bogotá: Universidad Externado de Colombia, 2014.

Nieto Garrido, E. El new public management y el Gobierno a través de contratos en el Reino Unido. En Revista de Administración Pública. Vol. 162, 2003.

Nieto Garrido, E. La financiación privada de obras y servicios públicos en el Reino Unido (The private finance initiative a public-private partnerships). En Revista de Administración Pública. Vol. 164, 2004.

Palomar Olmeda, A. El contrato de colaboración público-privada. En A. Palomar Olmeda, A. y De Álvaro Montero, Á. (eds.), La colaboración público-privada: análisis avanzado de los problemas prácticos de esta modalidad contractual. Cizur-Menor: Aranzadi, 2011.

Ponce de León Salucci, S. El contrato de concesión de obra pública en la legislación chilena. En Revista de Derecho Público. Vol. 79, 2013.

Ramírez Arrayas, J. A. Concesiones de obras públicas. Análisis de la institucionalidad chilena. Santiago: Abeledo-Perrot, 2010.

Román MÁrquez, A. El riesgo en las concesiones de obras y servicios públicos. Orígenes, evolución y situación actual en el ordenamiento jurídico comunitario. En Revista Española de Derecho Administrativo. Vol. 182, 2017.

Rufián Lizana, D. Manual de concesiones de obras públicas. Santiago: Fondo de Cultura Económica, 1999.

Rufián Lizana, D. Manual de concesiones de obras públicas. 2. ${ }^{a}$ ed. Santiago: Andros, 2018.

Sanz Gandasegui, F. El concepto del contrato de concesión de obras públicas. En MenénDEZ Menéndez, A. (ed.), Instrumentos españoles de colaboración público-privada: el contrato de concesión de obras públicas. 2. ${ }^{a}$ ed. Cizur-Menor: Civitas, 2010.

Valdivia Olivares, J. M. Manual de derecho administrativo. Valencia: Tirant lo Blanch, 2018.

VArgas Fritz, J. F. La concesión de obras públicas. Santiago: La Ley, 1997.

Viera Álvarez, C. Libre iniciativa económica y Estado social. Santiago: Legal-Publishing, 2013.

Yescombe, E. R. Public-Private Partnerships: Principles of Policy and Finance. Oxford: Butterworth-Heinemann, 2007. 